Arc. Com. Health • Juni 2018

ISSN: 2527-3620

\title{
UJI EFEKTIVITAS BATU VULKANIK DAN ARANG SEBAGAI MEDIA FILTER PENGOLAHAN AIR LIMBAH LAUNDRY DENGAN MENGGUNAKAN SISTEM PENGOLAHAN CONSTRUCTED WETLAND
}

\author{
Made Pasek Arya Suwahdendi *, I Gede Herry Purnama \\ Program Studi Kesehatan Masyarakat Fak. Kedokteran Universitas Udayana \\ *email: arya_suwahdendi@yahoo.com
}

\begin{abstract}
ABSTRAK
Usaha laundry saat ini tumbuh dengan pesat sehingga berpotensi untuk mencemari lingkungan karena air limbah yang dihasilkan seringkali dibuang ke badan air tanpa diolah terlebih dahulu. Salah satu pengolahan limbah yang dapat digunakan pada usaha laundry khususnya yang ada di Bali adalah sistem pengolahan air limbah model constructed wetland. Pada penelitian ini diketahui efektivitas model pengolahan air limbah Vertical Flow Subsurface Flow Constructed Wetland yang menggunakan media filter batu vulkanik kintamani dan arang kayu, serta menggunakan tanaman serai (Cymbopogon citratus) dalam mengolah air limbah laundry yang diukur berdasarkan parameter Total Fosfat dan Amonia. Hasil penelitian menunjukkan efektivitas sistem penurunan Total Fosfat dan Amonia selama 5 minggu pada masing-masing reaktor, yaitu; reaktor 1 ( $50 \%$ batu vulkanik, 50\% arang) sebesar 26,69\%, reaktor 2 (75\% batu vulkanik, 25\% arang) sebesar 37,32\%, reaktor 3 (25\% batu vulkanik, $75 \%$ arang) sebesar 20,94\%, reaktor 4 (100\% batu vulkanik) sebesar $26,91 \%$, reaktor 5 (100\% arang) sebesar $55,17 \%$. Berdasarkan hasil penelitian, reaktor sistem constructed wetland yang digunakan dalam penelitian ini belum efektif dalam mengolah air limbah laundry, apabila diterapkan pada laundry lainnya akan menghasilkan kinerja yang lebih rendah karena nilai parameter air limbah pada laundry lainnya dapat lebih tinggi secara signifikan dibandingkan dengan laundry dalam penelitian ini.
\end{abstract}

Kata kunci : Constructed Wetland, Batu Vulkanik, Arang, Total Fosfat, Amonia

\begin{abstract}
Laundry business is currently growing rapidly so that it has the potential to pollute the environment because the wastewater produced is often discharged into water bodies without being treated first. One of the waste treatment that can be used in the laundry business especially in Bali is the constructed wetland wastewater treatment system. In this research, it is known the effectiveness of the Vertical Flow Subsurface Flow Constructed Wetland wastewater treatment model using kintamani volcanic rock and wood charcoal filter media, and using lemongrass plants (Cymbopogon citratus) in treating laundry wastewater measured by the parameters of Total Phosphate and Ammonia. The results showed the effectiveness of the Total Phosphate and Ammonia reduction system for 5 weeks in each reactor, namely; reactor 1 (50\% volcanic rock, 50\% charcoal) by 26.69\%, reactor 2 (75\% volcanic rock, $25 \%$ charcoal) by $37.32 \%$, reactor 3 (25\% volcanic rock, $75 \%$ char) by $20,94 \%$, reactor 4 (100\% volcanic rock) by $26.91 \%$, reactor 5 (100\% charcoal) by $55.17 \%$. Based on the results of the study, the constructed wetland reactor system used in this study is not yet effective in treating laundry wastewater, if applied to other laundry it will produce lower performance because the value of the wastewater parameters in other laundry can be significantly higher compared to laundry in this study.
\end{abstract}

Keywords : Constructed Wetland ; Volcanic Stone ; Charcoal ; Amonia

\section{PENDAHULUAN}

Di Bali usaha laundry hingga saat ini belum terdata secara pasti jumlahnya, namun perkembangan usaha laundry mencapai setiap daerah perkotaan maupun pedesaan di Kabupaten dan Kota di seluruh Bali. Banyaknya usaha laundry tersebut berpotensi untuk mencemari lingkungan khususnya perairan karena air limbah yang dihasilkan dari sisa proses laundry seringkali langsung dibuang ke badan air tanpa mengalami pengolahan.

Limbah laundry yang mengandung deterjen berpotensi mencemari lingkungan dan membahayakan kesehatan lingkungan sekitarnya karena limbah tersebut memiliki konsentrasi fosfat, surfaktan, amonia dan nitrogen serta kadar BOD dan COD yang 
tinggi, hal ini akan berdampak pada penurunan LC50 yang berarti limbah tersebut berifat toksik bagi lingkungan dan biota didalamnya (Esmeralda dkk, 2012).

Tiap usaha laundry dapat menghasilkan limbah cair yang memiliki konsentrasi Total Fosfat sebesar 18,07-19,86 $\mathrm{mg} / \mathrm{L}$ (Uliantoro dkk, 2010). Tingginya kandungan fosfat dalam limbah laundry tersebut, berperan dalam terjadinya eutrofikasi yang menyebabkan alga boom pada perairan serta dapat menurunkan kandungan oksigen terlarut sehingga akan mengakibatkan kematian terhadap biota air (Tectona, 2011). Untuk meminimalisir dampak tersebut diperlukan upaya pengolahan terhadap air limbah laundry. Salah satu pengolahan limbah yang dapat digunakan pada usaha laundry adalah sistem pengolahan air limbah model constructed wetland.

Sistem constructed wetlands mampu mengolah air limbah dengan berbagai perbedaan jenis polutan maupun konsentrasinya sehingga memungkinkan untuk pelaksanaan reuse dan recycling air limbah (Suprihatin, 2014). Berdasarkan penelitian yang dilakukan Zurita, et al (2006), efektivitas pengolahan air limbah dengan metode constructed wetlands mampu menurunkan konsentrasi nilai parameter fosfat lebih dari $66 \%$.

Constructed wetlands dapat menggunakan media filter batu vulkanik dan arang. Berdasarkan penelitian yang menggunakan media filter Batu Vulkanik Kintamani yang dilakukan oleh Padmanabha (2015), efektivitas penurunan total fosfat mencapai 57,53\%. Sedangkan pada penelitian Maretha N (2012) yang menggunakan kombinasi arang aktif dapat menurunkan nilai fosfat sebesar $51,13 \%$.

Tujuan dari penelitian ini adalah untuk mengetahui efektivitas model pengolahan air limbah constructed wetlands menggunakan media filter batu vulkanik dan arang dalam pengolahan air limbah kegiatan laundry.

\section{METODE}

Penelitian ini menggunakan desain penelitian quasi experimental dengan pretestposttest control-group design dan dilakukan 3 (tiga) kali pengulangan pada kelompok reactor gabungan. Pada penelitian ini dibagi menjadi 5 kelompok yaitu, 3 kelompok reaktor gabungan dan 2 kelompok reaktor kontrol yang hanya menggunakan 1 jenis media filter. Penelitian ini dilakukan untuk melihat efektivitas multimedia filter batu vulkanik dan arang dalam penurunan nilai parameter Total Fosfat, Amonia dan $\mathrm{pH}$ air limbah usaha laundry dengan menggunakan model pengolahan air limbah jenis Vertical Flow Subsurface Flow Constructed Wetland (VFSFCW).

Sistem VFSFCW dalam penelitian ini menggunakan ember berukuran 30 Liter, media filter yang digunakan adalah batu vulkanik kintamani dan arang kayu, serta tanaman yang digunakan adalah tanaman serai (Cymbopogon citratus). Pada reaktor 1 digunakan batu vulkanik 50\% dan arang $50 \%$, pada reaktor 2 batu vulkanik $75 \%$ dan arang $25 \%$, reaktor 3 menggunakan $25 \%$ batu vulkanik dan $75 \%$ arang, sedangkan pada reaktor 4 dan 5 menggunakan batu vulkanik 100\% dan arang $100 \%$. Air limbah laundry dialirkan 
Arc. Com. Health • Juni 2018

ISSN: 2527-3620

Vol. 5 No. $1: 67$ - 76

ke 11 reaktor air limbah dengan HLR setelah pengolahan sebanyak 5 kali uji

sebesar $9 \mathrm{ml}$ per menit.

Pada penelitian ini dilakukan secara berkala setiap minggu selama 5 minggu.

pengujian laboratorium pada sampel sebelum pengolahan sebanyak 2 kali dan

HASIL

Kualitas Air Limbah Laundry Sebelum Pengolahan

Tabel 1 Nilai Parameter Air Limbah Laundry Sebelum Diolah

\begin{tabular}{cccccc}
\hline Para-meter & P1 & P2 & A & BM & S \\
\hline Fosfat & 0,49 & 21,05 & 10,77 & - & $\mathrm{mg} / \mathrm{L}$ \\
Amonia & 3,14 & 2,19 & 2,66 & $5 *$ & $\mathrm{mg} / \mathrm{L}$ \\
pH & 7,3 & 8,69 & 8,00 & $6-9 *$ & - \\
\hline
\end{tabular}

*Berdasarkan Peraturan Gubernur Bali No. 16 Tahun 2016

**Keterangan: $\mathrm{P}=$ Hasil Pengujian, $\mathrm{A}=$ Rata-Rata, $\mathrm{BM}=$ Baku Mutu, $\mathrm{S}=$ Satuan

Berdasarkan Tabel 1 diketahui $\mathrm{mg} / \mathrm{L}$ sedangkan pada rata-rata nilai bahwa nilai parameter air limbah yang dihasilkan Laundry CV Bali Kandi sangat tinggi pada nilai parameter Total Fosfat dengan rata-rata nilai parameter 10,77 parameter Amonia dan $\mathrm{pH}$ sudah memenuhi kriteria baku mutu standar yang ditetapkan pada Peraturan Gubernur Bali No. 16 Tahun 2016.

Kualitas Air Limbah Laundry Setelah Pengolahan

Tabel 2 Nilai Parameter Air Limbah Laundry Setelah Pengolahan

\begin{tabular}{ccccc}
\hline \multirow{2}{*}{ Sampel } & \multicolumn{3}{c}{ Nilai Parameter $(\mathrm{mg} / \mathrm{L})$} \\
\cline { 3 - 5 } \multicolumn{1}{c}{ R1 } & Fosfat & Amonia & $\mathrm{pH}^{* *}$ \\
\hline \multirow{2}{*}{ BM } & - & $5^{*}$ & $6-9^{*}$ \\
& A & 10,77 & 2,66 & 8 \\
& M1 & 3,15 & 2,43 & 7,23 \\
& M2 & 1,52 & 3,71 & 7,37 \\
& M3 & 2,24 & 3,47 & 6,84 \\
& R2 & 0,98 & 3,59 & 7,17 \\
& M4 & 1,87 & 3,10 & 7,16 \\
& M5 & 3,09 & 3,29 & 7,24 \\
M1 & 0,35 & 2,66 & 7,25 \\
R3 & 1,89 & 2,75 & 7,25 \\
& M2 & 1,40 & 3,37 & 7,33 \\
& M3 & 1,72 & 2,54 & 6,99 \\
M4 & 8,53 & 5,75 & 7,43
\end{tabular}




\begin{tabular}{|c|c|c|c|c|}
\hline \multicolumn{2}{|c|}{ M2 } & 1,76 & 3,37 & 7,52 \\
\hline \multirow[b]{4}{*}{$\mathrm{R} 4$} & M3 & 2,39 & 2,28 & 7,15 \\
\hline & M4 & 1,35 & 3,16 & 7,33 \\
\hline & M5 & 1,37 & 2,69 & 6,95 \\
\hline & M1 & 1,27 & 6,95 & 7,30 \\
\hline \multirow{9}{*}{ R5 } & M2 & 0,83 & 2,37 & 7,31 \\
\hline & M3 & 1,18 & 2,68 & 6,97 \\
\hline & M4 & 1,21 & 3,77 & 7,50 \\
\hline & M5 & 2,85 & 1,89 & 6,67 \\
\hline & M1 & 6,03 & 2,3 & 7,09 \\
\hline & M2 & 2,60 & 1,54 & 7,33 \\
\hline & M3 & 1,60 & 2,39 & 7,03 \\
\hline & M4 & 1,55 & 1,12 & 7,00 \\
\hline & M5 & 1,12 & 1,32 & 6,69 \\
\hline
\end{tabular}

*Berdasarkan Peraturan Gubernur Bali No. 16 Tahun 2016

**Tidak memiliki Satuan

${ }^{* * * K e t e r a n g a n: ~ A=R a t a-R a t a ~ S e b e l u m ~ D i o l a h, ~ B M=B a k u ~ M u t u, ~ M=M i n g g u, ~ R=R e a k t o r . ~}$

Berdasarkan hasil nilai parameter

pada Tabel 2, didapatkan hasil perhitungan persentase efektivitas nilai parameter dan efektivitas sistem pada masing-masing Tabel 3 Efektivas Reaktor Selama 5 Minggu reaktor selama 5 minggu yang dapat dilihat pada Tabel 3, sebagai berikut:

\begin{tabular}{|c|c|c|c|c|}
\hline \multirow{2}{*}{\multicolumn{2}{|c|}{ Reaktor }} & \multicolumn{2}{|c|}{ Efektivitas Parameter (\%) } & \multirow{3}{*}{$\begin{array}{l}\text { ES (\%) } \\
39,70\end{array}$} \\
\hline & & \multirow{2}{*}{$\begin{array}{c}\text { Fosfat } \\
70,75\end{array}$} & \multirow{2}{*}{$\begin{array}{c}\text { Amonia } \\
8,65\end{array}$} & \\
\hline R1 & M1 & & & \\
\hline & M2 & 85,89 & $-39,47$ & 23,21 \\
\hline & M3 & 79,20 & $-30,45$ & 24,38 \\
\hline & M4 & 90,90 & $-34,96$ & 27,97 \\
\hline & M5 & 82,64 & $-16,54$ & 33,05 \\
\hline \multirow[t]{5}{*}{ R2 } & M1 & 71,31 & $-23,68$ & 23,81 \\
\hline & M2 & 96,75 & 0,00 & 48,38 \\
\hline & M3 & 82,45 & $-3,38$ & 39,53 \\
\hline & M4 & 87,00 & $-26,69$ & 30,15 \\
\hline & M5 & 84,03 & 4,51 & 44,27 \\
\hline \multirow[t]{5}{*}{ R3 } & M1 & 20,80 & $-116,17$ & $-47,68$ \\
\hline & M2 & 83,66 & $-26,69$ & 28,48 \\
\hline & M3 & 77,81 & 14,29 & 46,05 \\
\hline & M4 & 87,47 & $-18,80$ & 34,33 \\
\hline & M5 & 87,28 & $-1,13$ & 43,08 \\
\hline
\end{tabular}


Arc. Com. Health Juni 2018

ISSN: 2527-3620

R4

$$
\text { M1 }
$$

88,21

$-161,28$

Vol. 5 No. $1: 67$ - 76

M2

92,29

10,90

$-36,54$

M3 89,04

$-0,75$

51,60

M4

88,77

$-41,73$

44,15

M5

73,54

28,95

23,52

R5

M1

44,01

13,53

51,24

M2

75,86

42,11

28,77

M3

85,14

10,15

58,98

M4

85,61

57,89

47,65

M5

89,60

50,38

71,75

69,99

*Keterangan: ES= Efektivitas Sistem dalam Persen (\%), M=Minggu, R=Reaktor.

Berdasarkan Tabel 2 dan Tabel 3 untuk parameter Fosfat diketahui bahwa pada reaktor 1 , reaktor 2 , reaktor 3 , dan reaktor 5 nilai parameter total fosfat selama 5 minggu penelitian cendrung mengalami penurunan, sementara pada reaktor 4 total fosfat nilai parameter total fosfat cendrung mengalami peningkatan. Namun, nilai total fosfat dari kelima reaktor tersebut masih lebih baik bila dibandingkan dengan nilai total fosfat air limbah sebelum diolah. Penurunan tertinggi nilai parameter Total Fosfat terjadi pada reaktor 2 di minggu 2 dengan hasil pengujian sebesar $0,35 \mathrm{mg} / \mathrm{L}$ dan persentase efektivitasnya yaitu $96,75 \%$. Sedangkan, penurunan terendah terjadi pada reaktor 3 di minggu 1 dengan hasil pengujian sebesar $8,53 \mathrm{mg} / \mathrm{L}$ dan persentase efektivitasnya yaitu $20,8 \%$.

Pada parameter amonia diketahui bahwa terjadi penurunan nilai parameter pada reaktor 5 (kontrol) dan tidak terjadi penurunan yang berarti pada reaktor 1 , reaktor 2, reaktor 3 dan reaktor 4 selama 5 minggu. Pada reaktor 1, reaktor 2, reaktor 3 dan reaktor 4 hampir di setiap minggunya hasil pengujian nilai parameter amonia diatas nilai parameter air limbah sebelum diolah. Nilai parameter amonia yang melebihi standar baku mutu terjadi pada reaktor 4 di minggu 1 dengan hasil pengujian sebesar 6,95 $\mathrm{mg} / \mathrm{L}$ dengan persentase efekitivitas $-161,28 \%$. Penurunan nilai parameter tertinggi terjadi pada reaktor 5 di minggu 4 sebesar 1,12 mg dengan persentase efektivitas $57,89 \%$.

Setelah dilakukan perhitungan persentase efektivitas pada nilai parameter Total Fosfat dan Amonia, diketahui persentase efektivitas penurunan Total Fosfat pada masing-masing reaktor selama 5 minggu yaitu; reaktor 1 sebesar 81,90\%, reaktor 2 sebesar $84,30 \%$, reaktor 3 sebesar $71,41 \%$, reaktor 4 sebesar $86,39 \%$, dan reaktor 5 sebesar $76,05 \%$. Persentase efektivitas penurunan Amonia pada tiap reaktor yaitu; reaktor 1 sebesar $-22,52 \%$, reaktor 2 sebesar $-9,67 \%$, reaktor 3 sebesar $29,53 \%$, reaktor 4 sebesar $-32,56 \%$, dan reaktor 5 sebesar 34,29\%. Dari efektivitas tiap nilai parameter didapat rata-rata persentase efektivitas sistem masingmasing reaktor selama 5 minggu, yaitu; reaktor 1 sebesar 26,69\%, reaktor 2 sebesar $37,32 \%$, reaktor 3 sebesar $20,94 \%$, reaktor 4 sebesar $26,91 \%$, reaktor 5 sebesar $55,17 \%$. 


\section{DISKUSI}

\section{Kualitas Air Limbah Laundry Sebelum Pengolahan}

Kualitas air limbah yang dihasilkan dari laundry CV Bali Kandi sudah memenuhi standar baku mutu pada parameter Amonia dan $\mathrm{pH}$. Rata-rata nilai parameter Amonia sebesar 2,66 mg/L masih dibawah baku mutu yang ditetapkan dalam Peraturan Bali Nomor 16 Tahun 2016 yaitu sebesar $5 \mathrm{mg} / \mathrm{L}$ dan ratarata nilai parameter $\mathrm{pH}$ sebesar 8 yang hampir mendekati basa tetapi masih memenuhi baku mutu yaitu 6-9.

Namun, pada parameter Total Fosfat memiliki rata-rata nilai parameter yang sangat tinggi yaitu sebesar 10,77 $\mathrm{mg} / \mathrm{L}$. Menurut penelitian yang dilakukan Uliantoro dkk, (2010) nilai parameter Total fosfat yang terkandung dalam air limbah laundry sangat tinggi dan diatas dari kandungan air limbah dalam penelitian ini, yaitu sebesar 18,07-19,86 mg/L. Kadar fosfat dalam perairan alami yang memiliki tingkat kesuburan rendah adalah 0,00050,02 mg/L dan bila melebihi kadar tersebut tentunya akan meningkatkan kesuburan perairan sehingga menyebabkan tingginya pertumbuhan tanaman air yang tidak terkendali serta akan menyebabkan eutrofikasi di perairan (Suyasa, 2015). Keadaan eutrofikasi dalam perairan dapat mengakibatkan kematian biota yang ada didalamnya, hal tersebut dikarenakan tanaman air yang ada dalam perairan dapat menghabiskan oksigen dalam air pada malam harinya dan saat di siang hari pancaran sinar matahari ke dalam air juga akan berkurang akibat terhalangnya sinar matahari untuk masuk ke dalam air, sehingga proses fotosintesis berkurang dan oksigen yang terlarut dalam air juga berkurang (Yunarsih, 2013).

Nilai parameter Total Fosfat yang tinggi disebabkan oleh penggunaan produk laundry. Produk laundry yang digunakan oleh laundry CV Bali Kandi seperti produk laundry konvensional. Produk konvesional mengandung bahan aktif surfaktan yang digunakan terpisah ataupun dikombinasikan seperti Alkyl Benzene Sulfonate, Linier Alkyl Benzene Sulfonate, dan Alpha Olefin Sulfonate, namun selain menggunakan produk tersebut pihak laundry juga menggunakan produk yang berasal dari supplier yang mengandung bahan aktif seperti Coconut Diethanolamide, Cocamidopropyl Betaine, Sodium lauryl ether sulphate, Linier Alkyl Benzene Sulfonate, dan Nonylphenol. Beragamnya jenis produk laundry yang digunakan oleh CV Bali Kandi mengakibatkan perubahan dan tidak menentunya kandungan air limbah yang dihasilkan (Effendi, 2003). Kandungan LAS dalam deterjen yang digunakan oleh laundry CV Bali Kandi juga berpengaruh pada kerusakan membran organisme dan mematikan bakteri-bakteri yang berguna di perairan sehingga dapat mempengaruhi konsentrasi Total Fosfat dan Amonia dalam air limbah (Hudori, 2008).

\section{Kinerja Reaktor Constructed Wetland}

Efektivitas penurunan nilai parameter Total fosfat sudah baik, karena semua hasil pengujian setelah pengolahan pada masing-masing reaktor ditiap minggunya selama 5 minggu mencapai hasil dibawah dari hasil pengujian air limbah sebelum pengolahan atau bisa 
disebut terjadi penurunan nilai parameter Total Fosfat setelah dilakukan pengolahan air limbah. Pada tiap reaktor dari reaktor 1 hingga reaktor 5 memiliki hasil yang berbeda pada tiap minggunya. Efektivitas penurunan nilai parameter Total fosfat tertinggi terjadi pada reaktor 2 di minggu 2 sebesar $96,75 \%$. Rata-rata efektivitas semua reaktor pada parameter total fosfat, yaitu; reaktor 1 sebesar $81,90 \%$, reaktor 2 sebesar $84,30 \%$, reaktor 3 sebesar $71,41 \%$, reaktor 4 sebesar 86,39\%, dan reaktor 5 sebesar $76,05 \%$. Semua hasil efektivitas dari semua reaktor rata-rata diatas $70 \%$, hasil tersebut diatas dari hasil penelitian yang dilakukan Pillai (2012) yaitu sebesar 41\% yang menggunakan model VFSFCW dan tanaman yang sama dengan penelitian ini.

Pada parameter Amonia efektivitas penurunannya tidak memperlihatkan hasil yang baik. Hasil dari nilai parameter Amonia setelah pengolahan masih diatas dari hasil sebelum diolah. Hal tersebut disebabkan oleh berbagai faktor, seperti musim hujan yang terjadi saat penelitian ini dilaksanakan, ukuran media filter yang terlalu besar, serta pertumbuhan tanaman dan jumlah mikroorganisme di dalam reaktor juga berpengaruh terhadap kinerja reaktor dalam penurunan parameter amonia.

Efektivitas penurunan pada nilai parameter Amonia pada masing-masing reaktor selama lima minggu memiliki nilai yang sangat rendah namun hasilnya berbeda-beda hingga beberapa reaktor mencapai nilai negatif. Efektivitas sistem penurunan amonia selama 5 minggu pada reaktor 1 yaitu $-22,52 \%$, reaktor 2 yaitu $9,67 \%$, reaktor 3 yaitu $-29,53 \%$, reaktor 4
Vol. 5 No. $1: 67$ - 76

yaitu $-32,56 \%$, dan reaktor 5 yaitu 34,29\%, sangat berbanding terbalik dengan penelitian yang dilakukan oleh Singh dkk (2009), efesiensi VFSFCW dalam menurunkan kadar amonia mencapai $70,9 \%$. Hal tersebut bisa terjadi dikarenakan faktor cuaca hujan selama dilakukan penelitian, dimana air hujan yang masuk kedalam reaktor pengolahan air limbah sehingga dapat menyebabkan konsentrasi amonia berubah-ubah sesuai dengan perubahan suhu. Suhu sangat berperan penting dalam penyisihan konsentrasi amonia, hal tersebut dipertegas oleh penelitian yang dilakukan Fahmiati (2012) dengan hasil peningkatan suhu dapat meningkatkan penyisihan amonia dimana pada suhu $50^{\circ} \mathrm{C}$ efektivitas penyisihan amonia mencapai $96 \%$, begitu juga sebaliknya bila suhu menurun maka penyisihan amonia juga ikut menurun (Fahmiati, 2012). Pada cuaca hujan suhu lingkunga menjadi rendah, menyebabkan pertumbuhan bakteri menurun sehingga proses nitrifikasi berlangsung dengan lambat dan mengakibatkan konsentrasi amonia tinggi (Titiresmi dkk, 2006). Hampir tiap minggu selama penelitian ini dilaksanakan terjadi hujan, pada minggu 1 terjadi hujan dihari sebelum pengambilan sampel air limbah dilakukan sehingga hasil nilai parameter Amonia pada minggu pertama terbilang cukup tinggi dimana hasil dari reaktor 3 dan reaktor 4 menunjukan angka diatas baku mutu. Pada reaktor 3 nilai parameter Amonia sebesar $5,75 \mathrm{mg} / \mathrm{L}$ dan reaktor 4 sebesar 6,95 mg/L.

Dalam penelitian ini menggunakan media filter batu vulkanik berukuran 3$5 \mathrm{~cm}$ dan media filter arang berukuran 2-4 
cm, sedangkan ukuran media filter yang ideal untuk sistem pengolahan constructed wetland adalah 0,8-1,6 cm (Vymazal, 2002). Berarti ukuran media filter yang digunakan dalam penelitian ini dua kali sampai lima kali lebih besar dari yang seharusnya digunakan untuk mendapatkan hasil pengolahan yang lebih optimal. Ukuran media filter yang besar dapat memperbesar ruang antar media sehingga laju air limbah lebih cepat didalam sistem pengolahan air limbah. Laju air limbah yang cepat didalam sistem pengolahan menyebabkan waktu kontak air limbah dan media filter berlangsung singkat sehingga pengolahan bahan-bahan organik dan bahan lainnya tidak berlangsung secara optimal (Brown dkk, 2000). Kecepatan aliran air dalam reaktor sistem sangat mempengaruhi konsentrasi amonia, hal tersebut dipertegas oleh penelitian yang dilakukan oleh Nugroho dkk, (2004) dengan hasil yang menyatakan bahwa semakin besar laju aliran air pada reaktor sistem, maka semakin kecil penurunan konsentrasi amonia (Nugroho dkk, 2004).

Hal lain yang berpengaruh terhadap kurang kinerja reaktor untuk penurunan nilai parameter khususnya Amonia adalah kinerja tanaman, media filter dan mikroorganisme yang ada didalam sistem reaktor. Media filter yang berukuran besar menyebabkan terganggunya proses pertumbuhan tunas tanaman yang ditanam dalam beberapa reaktor sistem constructed wetland sehingga pertumbuhan tunas lambat dan sedikit. Hal tersebut juga menyebabkan jumlah mikroorganisme yang terdapat didalam reaktor sistem lebih sedikit dari jumlah yang seharusnya ketika ukuran filter dan jumlah pori-pori dalam filter sesuai dengan kondisi yang optimal selama sistem beroperasi dalam 5 minggu (Brown dkk, 2000). Kurang optimalnya degeradasi pada tanaman, media filter dan mikroorganisme tersebut menyebabkan efektivitas pada nilai parameter Amonia kurang baik. Dikarenakan, jumlah mikroorganisme yang sedikit menyebabkan proses nitrifikasi yang mengubah amonia menjadi nitrit kemudian diubah kembali menjadi nitrat oleh bakteri pada kondisi aerob menjadi kurang baik. Selain itu, jumlah tanaman yang bertambah sedikit juga mengurangi daya serap atau adsorbsi pada amonia (Hendayanto, 2008; Priya dkk, 2013).

\section{SIMPULAN}

Nilai parameter air limbah yang dihasilkan Laundry CV Bali Kandi sangat tinggi pada nilai parameter Total Fosfat dengan rata-rata nilai parameter 10,77 $\mathrm{mg} / \mathrm{L}$, sedangkan rata-rata nilai parameter Amonia 2,66 mg/L dan $\mathrm{pH} 8,0$ sudah memenuhi kriteria baku mutu standar.

\section{Dari persentase efektivitas} penurunan nilai parameter Total Fosfat dan Amonia di dapat rata-rata persentase efektivitas sistem pada masing-masing reaktor selama $5 \mathrm{minggu}$, yaitu; reaktor 1 sebesar 26,69\%, reaktor 2 sebesar 37,32\%, reaktor 3 sebesar 20,94\%, reaktor 4 sebesar $26,91 \%$, reaktor 5 sebesar $55,17 \%$. Sistem constructed wetland pada penelitan ini belum efektif dalam mengolah air limbah laundry karena belum mampu menurunkan nilai parameter amonia secara signifikan dan apabila diterapkan pada laundry 
Vol. 5 No. $1: 67$ - 76

lainnya akan menghasilkan kinerja yang lebih rendah karena nilai parameter air limbah pada laundry lainnya dapat lebih tinggi secara signifikan dibandingkan dengan laundry dalam penelitian ini.

\section{DAFTAR PUSTAKA}

Brown, D.S., dkk. (2000). Manual: Constructed Wetlands Treatment of Municipal Wastewaters. Ohio: Environmental Protection Agency. Effendi, H. (2003). Telaah Kualitas Air: Bagi Pengelolaan Sumber Daya danLingkungan Perairan. Yogyakarta: Kanisius.

Esmiralda, dkk. (2012). Pengaruh COD dan Surfaktan dalam Limbah Cair Laundri terhadap Nilai LC50. Jurnal Teknik Lingkungan UNAND, 9(1):110-114.

Fahmiati, S. (2012). Pengaruh Umpan Pada Penyisihan Amonia dari Air Limbah Menggunakan Kombinasi Proses Membran dan Ozonasi. Skripsi. Fakultas Teknik, Universitas Indonesia.

Hendayanto, E., dkk. 2007. Biologi Tanah. Pustaka Adipura: Yogyakarta.

Hudori. (2008). Pengolahan Air Limbah Laundry dengan Menggunakan Elektrokoagulasi. Tesis. Institut Teknologi Bandung, Bandung

Maretha N, A., dkk. (2014). Pengolahan Limbah Laundry dengan Penambahan Koagulan Polyalumunium Chloride (Pac) dan Filter. Jurnal Teknik Lingkungan, (4)3.

Nugroho, T., dkk. (2004). Desopsi Amoniak Pada Model Sungai. Universitas Sebelas Maret, Surakarta.
Padmanabha, G. (2015). Efektivitas Model Instalasi Pengolahan AirLimbah Vertical Flow Sub Surface FlowConstructed Wetland dalam Mengolah AirLimbah Kegiatan Laundry. Skripsi. Universitas Udayana, Denpasar.

Pillai, J., S., et al (2012). Decentralized Greywater Treatment for Nonpotable Reuse in a Vertical Flow Constructed Wetland.Department of Civil Engineering, College of Engineering, Thiruvananthapuram.

Priya, et al. (2013). Comparison of Different Types of Media for Nutrient Removal Efficiency in Vertical Upflow Constructed Wetlands. International Journal of Environmental Engineering and Management, 4(5): 405-416.

Singh, S., dkk. (2009). Performance of an anaerobic baffled reactor and hybrid constructed wetland treating highstrength wastewater in Nepal e a model for DEWATs. Ecol. Eng. 35, 654-660.

Supradata. (2005). Pengolahan Limbah Domestik Menggunakan Tanaman Hias Cyperus alternifolius dalam Sistem Lahan Basah Buatan Aliran BawahPermukaan (SSF-Wetlands). Tesis. Jurusan Ilmu Lingkungan, Universitas Diponegoro, Semarang. Suyasa, W.B. (2015). Pencemaran Air \& Pengolahan Air Limbah. Denpasar: Udayana University Press.

Tectona, J. (2011). Pemanfaatan Kayu Angsana (Pterocarpus indicus) Sebagai Arang Aktif untuk Pengolahan Limbah Laundry. 
Skripsi. Jurusan Teknik Lingkungan FTSP, ITS, Surabaya

Titiresmi, dkk. (2006). Teknologi Biofilter untuk Pengolahan Limbah Ammonia. J.Tek.Ling, 7(2):173-179.

Uliantoro, N., A., dkk. (2010). Potensi Daur Ulang Limbah Cair Cucian Pada Rumah Tangga Dengan Memanfaatkan Pengolahan Secara Fisik Menggunakan Downflow Packed-Bed Attached Growth Reactor. Jurusan Teknik Lingkugan Vymazal, J. (2002). The Use of SubSurface Constructed Wetlands for Wastewater Treatment in the Czech Republic: 10 Years Experience. Ecological Engineering, 18:633-646.

Yunarsih, N., M. (2013). Efektifitas Membran Khitosan Dari Kulit Udang Galah(Macrobanchium

Rosenbergii)Untuk Menurunkan Fosfat DalamAir Limbah Laundry. Tesis. Program Studi Kimia Terapan, Universitas Udayana, Denpasar.

Zurita, F., dkk. (2006). Performance of Laboratory-Scale Wetlands Planted with Tropical Ornamental Plants to Treat Domestik Wastewater. Water Qual. Res. J. Canada, 41(4):410-417. 